\title{
Particle-phase concentrations of polycyclic aromatic hydrocarbons in ambient air of rural residential areas in southern Germany
}

\author{
Md. Aynul Bari • Günter Baumbach • Bertram Kuch • \\ Günter Scheffknecht
}

Received: 18 May 2009 / Accepted: 8 November 2009/Published online: 9 January 2010

(C) The Author(s) 2010. This article is published with open access at Springerlink.com

\begin{abstract}
An important source of polycyclic aromatic hydrocarbons (PAHs) in residential areas, particularly in the winter season, is the burning process when wood is used for domestic heating. The target of this study was to investigate the particle-phase PAH composition of ambient samples in order to assess the influence of wood combustion on air quality in residential areas. $\mathrm{PM}_{10}$ samples (particulate matter $<10 \mu \mathrm{m}$ ) were collected during two winter seasons at two rural residential areas near Stuttgart in Germany. Samples were extracted using toluene in an ultrasonic bath and subsequently analysed by gas chromatography-mass spectrometry. Twenty-one PAH compounds were detected and quantified. The PAH fingerprints of different wood combustion emissions were found in significant amounts in ambient samples and high correlations between total PAHs and other wood smoke tracers were found, indicating the dominant influence of wood combustion on air quality in residential areas. Carcinogenic PAHs were detected in high concentrations and contributed $49 \%$ of the total PAHs in the ambient air. To assess the health risk, we investigated the exposure profile of
\end{abstract}

M. A. Bari $(\bowtie) \cdot$ G. Baumbach · G. Scheffknecht

Institute of Combustion and Power Plant Technology (IFK),

University of Stuttgart,

Pfaffenwaldring 23 ,

Stuttgart 70569, Germany

e-mail: bari@ifk.uni-stuttgart.de

B. Kuch

Institute of Sanitary Engineering,

Water Quality and Solid Waste Management,

University of Stuttgart,

Bandtäle 2,

Stuttgart 70569, Germany individual PAHs. The findings suggest that attention should be focused on using the best combustion technology available to reduce emissions from wood-fired heating during the winter in residential areas.

Keywords Air Quality · Domestic heating · Health risk · PAHs $\cdot \mathrm{PM}_{10} \cdot$ Wood combustion

\section{Introduction}

With the growing concern on the issue of global warming, wood combustion as a renewable energy source is becoming increasingly popular in residential areas for domestic heating. Unfortunately, wood combustion is an important source of organic particulate emissions. Among the organic carbon compounds of atmospheric aerosols, polycyclic aromatic hydrocarbons (PAHs) are prevalent constituents of atmospheric pollution. Several studies have been carried out worldwide (Schauer et al. 1996; Rogge et al. 1998; Schauer and Cass 2000; Oros and Simoneit 2001; Fine et al. 2002; Hays et al. 2003; Gullett et al. 2003; Primbs et al. 2008; Kleeman et al. 2008) to characterise PAHs and other organic compounds emitted from woodfired heating in residential areas. The rising prices and uncertain availability of fossil fuels for heating, such as petroleum and natural gas, together with environmental concerns have resulted in the increased use of wood in many developing as well as developed countries, such as Germany.

PAHs are complex mixtures of hundreds of chemicals, including the derivatives of PAHs (such as nitro-PAHs), oxygenated products and heterocyclic PAHs. They are formed from the incomplete combustion of organic matter, such as the burning of coal, petroleum, oil and wood (Yu 
and Hites 1981; Harvey 1997). In domestic wood firings, this incomplete combustion frequently occurs due to inhomogeneous, instationary burning conditions with inadequate mixing of the fuel and air and local combustion temperatures that are too low, resulting in PAHs and the formation and emission of soot (Baumbach 1996). In many cases, the volatile wood compounds do not burn properly but merely vaporise or pyrolyse partially and then condense in the exhaust gases (Struschka 1993). The condensate consists of high-molecular-weight hydrocarbons, including large numbers and high concentrations of PAHs that not only settle on the heat exchange surfaces but also on emitted particles, particularly on soot (Kamm and Röhm 1982). Therefore, smoke emitted from wood combustion can generate high concentrations of PAHs; for example, total PAHs cocentration of $3000 \mu \mathrm{g} / \mathrm{m}^{3}$ and benzo[a]pyrene concentration of $60 \mu \mathrm{g} / \mathrm{m}^{3}$ have been measured in the flue gas emissions from small residential stoves (Chow et al. 1994). Thus, residential wood combustion can result in very high emissions of inhalable particles and can be a very significant source of PAH containing atmospheric aerosols, particularly in winter months.

The modern gas and oil burners currently used for heating systems and hot water systems have relatively low PAH emissions (Hays et al. 2008, 2009). Similarly, modern residential wood boilers, which are automatically fed and controlled, as well as modern pellet stoves with continuous fuel feeding create PM emissions that are formed mainly by the vaporisation of ash particles; consequently, they have lower PAH emissions than manually fed boilers and wood stoves (Johannson et al. 2004; Tissari et al. 2008). However, during the winter, many people in residential villages use old manually fed wood boilers and chimney stoves. Depending on the users' behaviour, such firings can cause high $\mathrm{PAH}$ emissions (Tissari et al. 2008). PAH emissions due to such residential wood combustion contribute significantly to the total concentrations of PAHs in ambient air in residential villages (Freeman and Cattel 1990; Hellen et al. 2008).

PAHs are good tracers of anthropogenic sources to the atmosphere due to their low natural emission (Dachs et al. 1996; Nikolaou et al. 1984), and approximately $90 \%$ of PAH emissions are estimated to be anthropogenic (Harvey 1997). The environmental concern for PAHs comes from the awareness that several of these are carcinogens and are present in polluted air. The continuous interest in airborne PAHs is due to the results of laboratory studies which have found that benzo(a)pyrene and many other PAHs are carcinogenic (Jones and Leber 1980; Lee et al. 1981). Because of their carcinogenic effects, PAHs are now considered to be priority pollutants by both the United States Environmental Protection Agency (USEPA) and the
European Environmental Agency (EEA) (USEPA 1977; EC 2001).

In the residential villages of Germany, many people use $\log$ wood boilers with and without a heat storage tank for central heating. Additional heating is supplied mainly by manually fed chimney stoves, tiled stoves and open fire places. Our selected residential village of Dettenhausen is located $19 \mathrm{~km}$ south of Stuttgart and at the northern edges of the nature park area "Schoenbuch", which is a large forest in the state of Baden-Wuerttemberg, Germany. The word "Schoenbuch" means "nice beeches", and this forest comprises mainly beeches. These beeches supply the hardwood that is mostly used as solid biofuel for domestic heating. Dettenhausen is a community of about 5400 people and covers an area of $11 \mathrm{~km}^{2}$. Since people in this village can get hardwood easily from the forest, more than $90 \%$ of firewood used in this site is hardwood, mainly beech wood (confirmed by the official local chimney sweeper, Decker Roman in a personal communication, 2009). The other emission sources in this site are central heating with light oil and gas firing, but their emissions could be determined as being very low due to a good combustion quality (Bari et al. 2008). Further sources are low traffic and regional background load, which are not predominant in this village. During winter, when surface inversion conditions prevail, the particulate matter (PM) load over the village can be visually detected as coming from residential wood firings.

In the light of overwhelming evidence that PAHs from residential wood combustion are observed in the aerosol accumulation mode (Venkataraman et al. 2002; Hays et al. 2003; Kleeman et al. 2008 ), it should be mentioned that in the USA wood smoke studies have been carried out on fine particulate matter, and $\mathrm{PM}_{2.5}$ is considered to be the standard size fraction of particulate pollution. In Europe, regulatory limit values are based on particulate matter with an aerodynamic diameter $<10 \mu \mathrm{m}\left(\mathrm{PM}_{10}\right)$. High $\mathrm{PM}_{10}$ concentrations are limited in Germany, based on measurement. However, if high $\mathrm{PM}_{10}$ concentrations do exist in residential areas, then this would certainly be a cause of concern with respect to which part of these high $\mathrm{PM}_{10}$ concentrations are caused by wood combustion and what is their carcinogenic potential, as expressed by PAH content (i.e., benzo[a]pyrene). Based on emission measurements of wood combustion, it is well known that $>80 \%$ of the emitted PM has a grain size of $<1 \mu \mathrm{m}$ (Baumbach and Struschka 2005). If $\mathrm{PM}_{10}$ sampling is performed, then it can be assumed that $>70 \%$ of ambient PM has a size fraction $<1 \mu \mathrm{m}$, which has been found by cascade impactor measurements in a residential site (Bari 2009). Therefore, in our study we focused on the investigation of particle phase PAHs in ambient $\mathrm{PM}_{10}$ samples to determine the PAH load caused by wood combustion processes in residential areas. 


\section{Sampling methodology and chemical analysis}

\section{PAH emission fingerprints}

To obtain PAH fingerprints of different emission sources in residential areas and for comparison with emissions from urban traffic, we sampled flue gases from hardwood and softwood combustion systems used for domestic heating, from oil boilers used for central heating and from road dust at a traffic site. We also sampled the ambient air at a traffic site. To distinguish between hardwood and softwood tracer compounds, we collected six beech wood and five pine wood PM samples from the flue gases of a chimney oven installed in a residential house. To obtain the traffic PMbound PAH fingerprints, we collected $\mathrm{PM}_{10}$ samples from an urban high-intensity traffic site in Stuttgart and subsequently selected ten samples with high $\mathrm{PM}_{10}$ concentrations for PAH analysis. Road dust samples $(n=4)$ were collected using a special vacuum cleaner at the high traffic-impacted site of Stuttgart Neckartor. In addition, three flue gas samples from oil boilers were collected in the test facilities of the University of Stuttgart. The details of emission sampling are adapted from Bari et al. (2008).

\section{Ambient samplings}

Ambient $\mathrm{PM}_{10}$ samples were collected at a residential site in Dettenhausen from 1 November 2005 to 31 March 2006. Like many cities in southern Germany and, in particular, in the Schoenbuch region, Dettenhausen possesses a temperate climate with four distinct seasons, but with considerably less seasonal variation in temperature. Throughout the year, temperatures range from approximately $18^{\circ} \mathrm{F}\left(-8^{\circ} \mathrm{C}\right)$ during the night in January and February, the coldest months of the year, to approximately $80^{\circ} \mathrm{F}\left(22^{\circ} \mathrm{C}\right)$ during July afternoons. The wettest month of the year is November, with an average precipitation of $127 \mathrm{~mm}$, and the driest month of the year is September, when there is only an average of $75 \mathrm{~mm}$ of precipitation. The average annual precipitation is about $1260 \mathrm{~mm}$. Prevailing winds are southwesterly and weak $(1.6 \mathrm{~m} / \mathrm{s})$, resulting in an inefficient dispersion of atmospheric pollutants and short-range transport.

During the winter of 2006/2007, $\mathrm{PM}_{10}$ sampling was also performed at another residential site, Bechtoldsweiler $(550 \mathrm{~m}$ a.s.1.1, area $2.78 \mathrm{~km}^{2}$, no. of inhabitants 750 ), which is located near Hechingen in the state of Baden-Wuerttemberg. The location of the two selected residential sites in Germany is shown in Fig. 1. The 2005/2006 winter was very cold, with the minimum temperature ranging from 2 to $-14^{\circ} \mathrm{C}$, and the area was covered with snow for most of January and February. The frequent occurrence of surface inversions limited the dispersion of pollutants within the atmosphere. In contrast, the winter was relatively weak during 2006/07.
The $\mathrm{PM}_{10}$ sampling was carried out using low-volume samplers (LVS3, Leckel, Germany) in accordance with the reference method defined in the European Standard EN 12341:1998 (CEN 1998), and the chosen filters were glass fibre filters (GF; diameter $50 \mathrm{~mm}$; Whatman, UK). The air inlet was located $2.5 \mathrm{~m}$ above ground level. The pumped volume flow rate was $2.3 \mathrm{~m}^{3} / \mathrm{h}$. To obtain sufficient material on the filter due to the low concentrations of PAHs, the sampling duration was selected for $48 \mathrm{~h}$ during weekdays and $72 \mathrm{~h}$ over the weekends. Prior to sampling, the filters were baked at $300-550^{\circ} \mathrm{C}$ for at least $6 \mathrm{~h}$ to remove any traces of organics. After sampling, the filters were packed in petri dishes covered with aluminum foil to protect them from sunlight. In accordance with the manufacturer's specifications (CEN 1998), the filters were conditioned in a weighing chamber for $48 \mathrm{~h}$ under controlled conditions before and after sampling. The weight of each filter was determined using an analytical balance (MC 210 P; Sartorius, Goettingen, Germany) with an accuracy of $\pm 0.02 \mathrm{mg}$. The filters were stored in a refrigerator $\left(-18^{\circ} \mathrm{C}\right)$ to prevent volatilisation of the lowermolecular-weight compounds before analysis.

\section{Chemical analysis}

The collected filter samples were analysed by gas chromatography-mass spectrometry (GC-MS). A filter aliquot containing half of a filter was transferred into a $5-\mathrm{ml}$ glass vial and spiked with $100 \mu \mathrm{l}$ of an isotope-labelled standard solution containing 16 perdeuterated PAHs according to USEPA (each compound $1 \mathrm{ng} / \mu \mathrm{l}$ in toluene) and $100-\mu 1$ phthalate standards ( $\mathrm{d}^{4}$-dibutylphthalate and $\mathrm{d}^{4}$-benzylbutylphthalate, $2 \mathrm{ng} / \mu \mathrm{l}$ in methanol). The filters were extracted with toluene for $30 \mathrm{~min}$ in an ultrasonic bath (Bransonic, Shelton, CT). The extracts were then concentrated under a gentle stream of clean nitrogen at the dry $\left(40^{\circ} \mathrm{C}\right)$ condition and made up to an exact volume of $100 \mu$ l. Standards of PAHs were purchased from LGC Promochem (Wesel, Germany). The extracts from the $\mathrm{PM}_{10}$ filter samples were analysed using a Hewlett Packard 6890 gas chromatograph (Palo Alto, CA) coupled with an Agilent 5973 mass selective detector (MSD; Agilent Technologies, Santa Clara, CA) operating in full scan mode. Details on the configuration and temperature profile of the GC system are described in Bari et al. (2008).

The isotope-labelled PAH standard solution containing naphthalene- $\mathrm{d}_{8}$, acenaphthylene- $\mathrm{d}_{8}$, acenaphthene- $\mathrm{d}_{10}$, fluorene- $\mathrm{d}_{10}$, phenanthrene- $\mathrm{d}_{10}$, anthracene- $\mathrm{d}_{10}$, fluoranthene$d_{10}$, pyrene- $d_{10}$, chrysene- $d_{10}$, benzo[a]anthracene- $d_{10}$, benzo [k]fluoranthene- $\mathrm{d}_{12}$, benzo[b]fluoranthene- $\mathrm{d}_{12}$, benzo[a]pyrene- $\mathrm{d}_{12}$, dibenzo[a,h]anthracene- $\mathrm{d}_{14}$, indeno[1,2,3-cd]pyrene$d_{12}$ and benzo[ghi]perylene- $d_{12}$ was used for quantification. Retene was quantified based on five-point standard calibra- 
tion curves using an authentic standard for retene. Each species was identified and quantified based on its retention time and integrated area of its molecular ion fragments compared to that of the appropriate standard. For the blank filter samples, measurement results, especially for naphthalene and phenanthrene, were generally below the quantification limit and, therefore, no blank correction was applied to the measurement results.

\section{Results}

Source fingerprints of PAHs were determined for softwood and hardwood combustion emissions and compared with those of other emission sources, such as those from central heating systems with light oil and gas firing, traffic, and road dust. The predominant PAHs found in the softwood combustion emissions were retene (Ret), benzo[ghi]perylene (BghiP), indeno[1,2,3-cd]pyrene (IP), benzo[a]pyrene $(\mathrm{BaP})$, benzo[e]pyrene $(\mathrm{BeP})$, benzo[k]fluoranthene $(\mathrm{BkF})$ and benzo[b]fluoranthene $(\mathrm{BbF})$; benzo[a]anthracene $(\mathrm{BaA})$, phenanthrene (Phe), anthracene (Ant), pyrene (Py), fluoranthene (Flut) and chrysene (Chr) were found in smaller proportions. In contrast, hardwood combustion emissions contained significant amounts of Flut, Py, BaA and $\mathrm{Chr}$. These results are in good agreement with those from other studies (Freeman and Cattel 1990; Khalili et al.
1995). The PAH fingerprints for other emission sources are described in detail in Bari et al. (2008). In our study, the results are focused on the ambient concentrations and levels of PAHs in the residential areas.

Impact of wood combustion on ambient air quality

Many residents of the village of Dettenhausen, which is located in a forest-rich area, burn wood for domestic heating. This wood burning causes high $\mathrm{PM}_{10}$ concentrations in the ambient air, which annoys the inhabitants and results in complaints on air quality. During the cold winter months, people can smell a distinct 'wood smoke odour' in the air. Due to the availability of hardwood in the surrounding forests, people use more hardwood than softwood for the heating purposes. To obtain solid experimental data that would support measures for limiting this type of pollution, we investigated the organic composition of hardwood and softwood smoke emissions and the ambient composition of airborne PM samples to determine the relative contribution of wood smoke to the winter ambient air pollution. The average concentration of individual PAH compounds in the ambient $\mathrm{PM}_{10}$ samples and the PAH composition of different wood combustion flue gases from a residential chimney oven are shown in Fig. 2. According to published studies, the typical compounds obtained from wood combustion are Ret, Flut, Py,
Fig. 1 Study sampling sites in Germany of $\mathrm{PM}_{10}$ (particulate matter with an aerodynamic diameter $<10 \mu \mathrm{m})$. Dark areas are forests

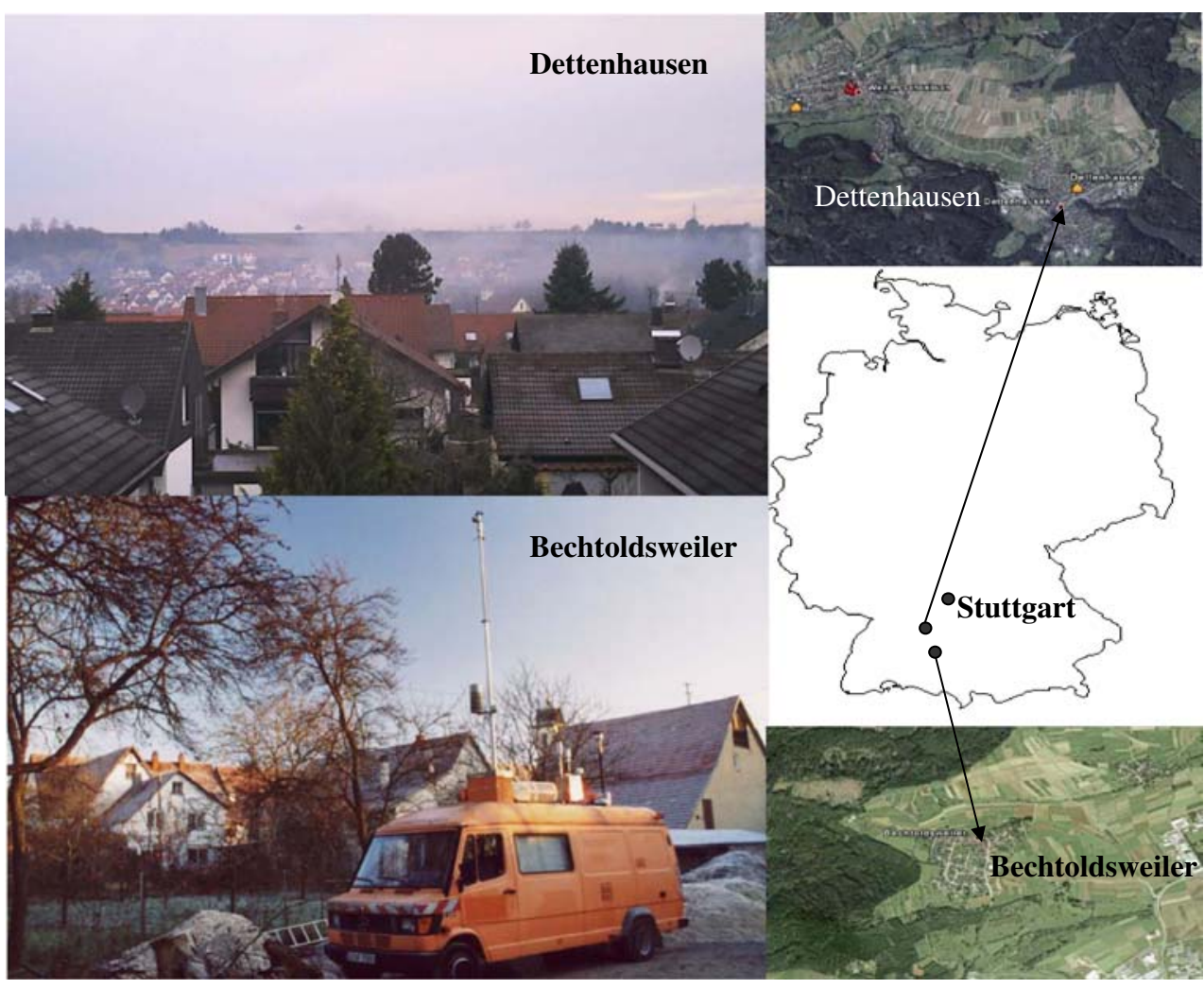


Fig. 2 Comparison of polycyclic aromatic hydrocarbon $(\mathrm{PAH})$ composition in wood smoke emissions and in ambient air in the residential site of Dettenhausen

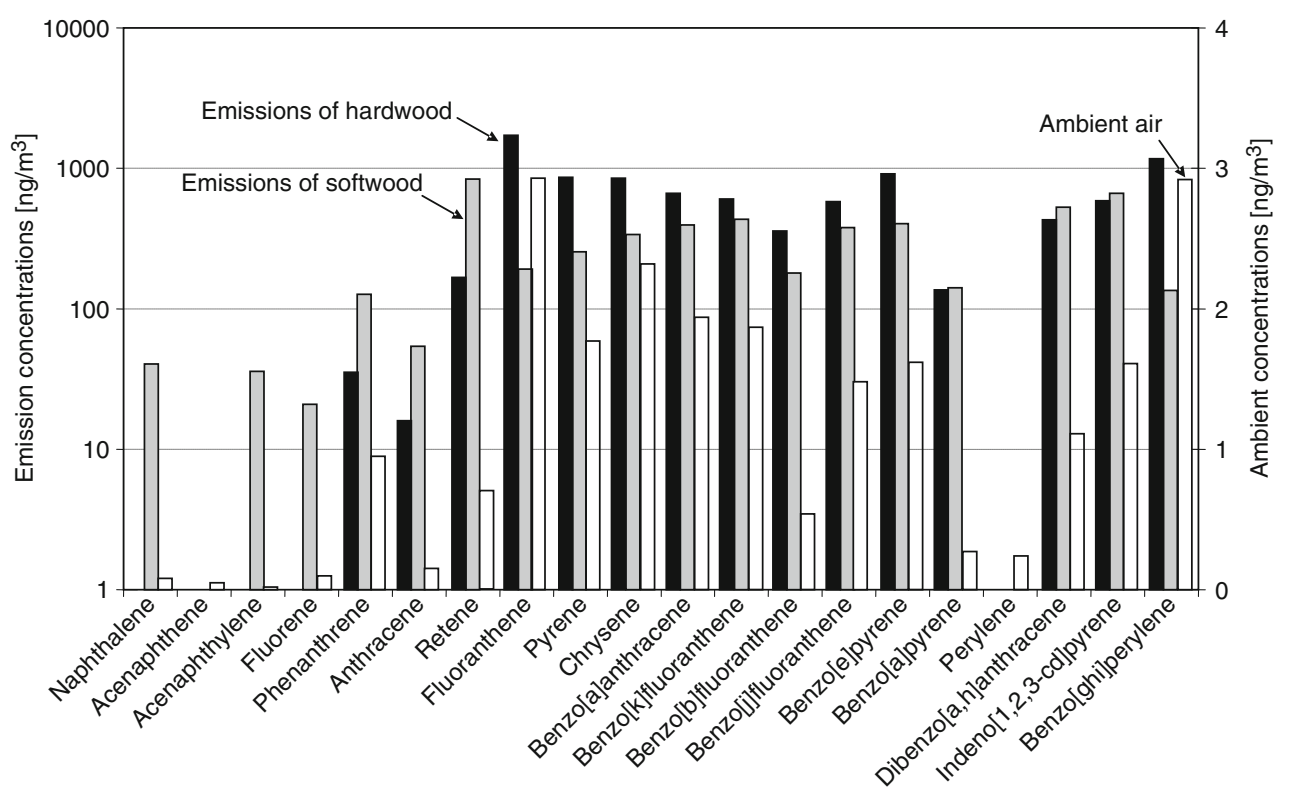

Ant, BaA, BaP and Chr (Ramdahl 1983; Khalili et al. 1995; Marbach and Baumbach 1998). We found that the PAH fingerprints of the hardwood and softwood combustion emissions were present at significant concentrations in ambient $\mathrm{PM}_{10}$ samples. As PAHs are not potential wood smoke tracers, the influence of wood combustion emissions was further examined with important tracer compounds, such as levoglucosan (Shafizadeh 1968; Locker 1988; Simoneit et al. 1999; Fraser and Lakshmanan 2000) and methoxyphenols; syringaldehyde and acetosyringone are specific markers for hardwood combustion (Hawthorne et al. 1992; Rogge et al. 1998; Schauer et al. 2001). In our study, levoglucosan (in underivatised form at $\mathrm{m} / \mathrm{z} 60$ ) was found in all $\mathrm{PM}_{10}$ samples. Due to poor GC chromatographic behaviour (i.e., tailing) in the underivatised form, levoglucosan was further detected with a derivatisation method to increase the analytical sensitivity. The ion fragments at $\mathrm{m} / \mathrm{z} 204$ and 217 of the levoglucosan-TMS (trimethylsilyl) derivative were used for better detection. The correlations of total PAHs and $\mathrm{BaP}$ with levoglucosan as well as the correlations of total PAHs with syringaldehyde and acetosyringone, respectively, measured in 42 ambient $\mathrm{PM}_{10}$ samples, are shown in Fig. 3. There were significant correlations between total PAHs $\left(R^{2}=0.73\right)$ and $\mathrm{BaP}\left(R^{2}=0.76\right)$ and levoglocosan, suggesting that smallscale wood combustion is the dominant source in the investigated residential site. Figure $3 \mathrm{~b}$ shows that there was a good correlations between total PAHs and syringaldehyde $\left(R^{2}=0.77\right)$ and acetosyringone $\left(R^{2}=0.85\right)$, respectively, which indicates that the influence of hardwood combustion
Fig. 3 Correlation between total PAHs and benzo[a]pyrene $(B a P)$ and levoglucosan, respectively (a), and between total PAHs and syringaldehyde and acetosyringone (b), respectively
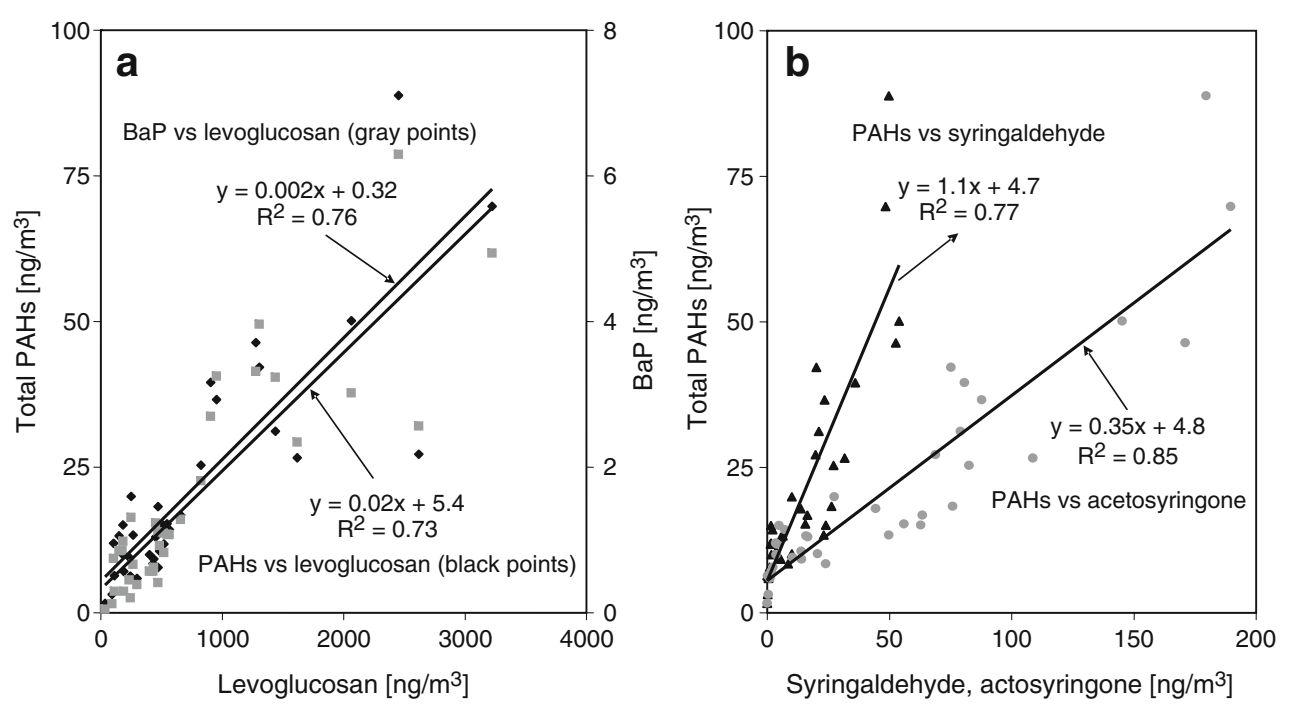
Fig. 4 Temporal ambient profiles of PAHs and $\mathrm{PM}_{10}$ in residential areas
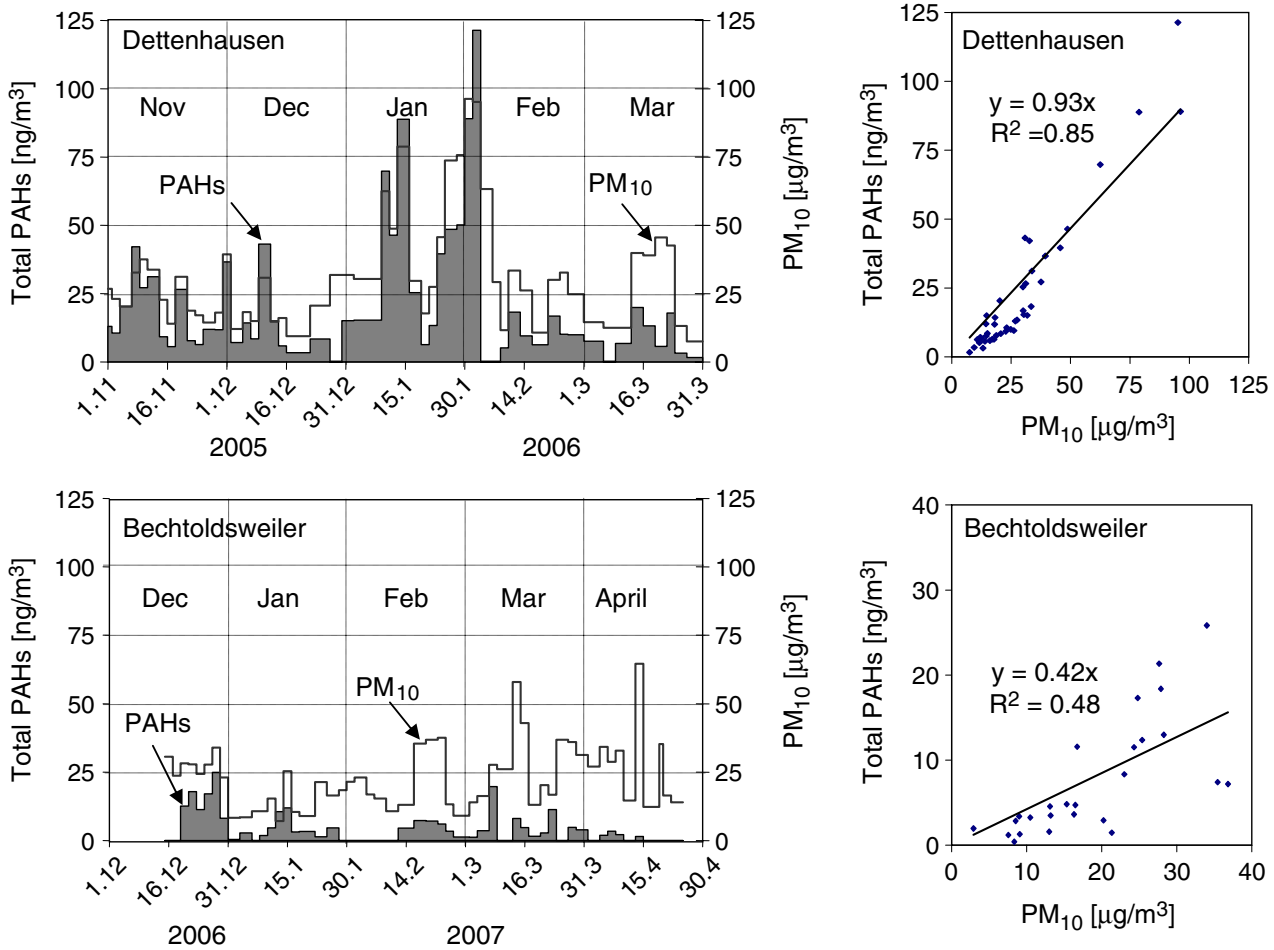

emissions is significant. Therefore, small-scale wood-fired domestic heating may contribute significant concentrations to ambient PAHs in the residential site.

\section{Ambient PAH concentrations}

The temporal ambient concentrations of total PAHs and $\mathrm{PM}_{10}$ in two residential villages during the winters 2005/06 and 2006/07 are depicted in Fig. 4. The average concentrations of total PAHs and $\mathrm{PM}_{10}$ at the beginning of the winter months (November, December) in Dettenhausen varied from 4 to $37 \mathrm{ng} / \mathrm{m}^{3}$ and 10 to $40 \mu \mathrm{g} / \mathrm{m}^{3}$, respectively. The highest peak concentrations of total PAHs and $\mathrm{PM}_{10}$ were observed from mid-January to early February due to the strong winter surface inversions that limited the dispersion of air pollutants. A good correlation $\left(R^{2}=0.85\right)$ was found between the average concentrations of total PAHs and $\mathrm{PM}_{10}$. The high winter concentrations were assumed to be caused by emissions from wood burning for domestic heating.

In contrast, due to the relatively weak winter scenario in 2006/2007, comparatively low PAHs and $\mathrm{PM}_{10}$ profiles were observed in Bechtoldsweiler. Although some high $\mathrm{PM}_{10}$ values were found in March and April of that year, the values do not correlate with the PAH concentrations, indicating emission sources other than wood combustion. These could be determined as overall background concentrations, since they were found at all regional background monitoring sites in Baden-Wuerttemberg state (LUBW 2009). Due to these low $\mathrm{PM}_{10}$ concentrations, we found a comparatively poor correlation $\left(R^{2}=0.48\right)$ at this residential site. During this mild winter, the $\mathrm{PM}_{10}$ concentrations caused by low heating activities in the residential area were relatively lower than the background $\mathrm{PM}_{10}$ concentrations. Therefore, the correlation between total PAHs (coming from heating activities) and the ambient $\mathrm{PM}_{10}$ concentrations was lower than that observed for the winter 2005/ 2006 in Dettenhausen $\left(R^{2}=0.85\right)$.

Table 1 shows the mean, median, minimum and maximum values for each PAH compound and for the concentrations of total PAHs and carcinogenic PAHs during the two winter seasons in the residential villages. Altogether, $21 \mathrm{PAH}$ compounds were quantified in 52 ambient particle-phase $\mathrm{PM}_{10}$ samples in Dettenhausen, and $20 \mathrm{PAH}$ compounds were quantified in 36 ambient $\mathrm{PM}_{10}$ samples in Bechtoldsweiler. During the winter of 2005/2006 in Dettenhausen, the average for the sum of $21 \mathrm{PAHs}$ was $23.0 \mathrm{ng} / \mathrm{m}^{3}$, with a maximum value of $121.4 \mathrm{ng} / \mathrm{m}^{3}$ and a minimum value of $1.6 \mathrm{ng} / \mathrm{m}^{3}$. The most dominant compounds found in the ambient air were Flut $(12.7 \%)$, Py (12.8\%), BaA (10.1\%), BkF (8.5\%), BbF (8.1\%), Chr (7.7\%), BaP (7.1\%), BghiP (7.0\%), with the eight other compounds representing about $25 \%$ of the concentrations of total PAHs. On the other hand, during the winter of 2006/2007, we observed comparatively low concentrations (mean $6.9 \mathrm{ng} / \mathrm{m}^{3}$, range $0.4-25.8 \mathrm{ng} / \mathrm{m}^{3}$ ) of total PAHs in 
Table 1 Mean, median, minimum and maximum concentrations (in $\mathrm{ng} / \mathrm{m}^{3}$ ) of each PAH compound at the two residential sites

\begin{tabular}{|c|c|c|c|c|c|c|c|c|}
\hline \multirow[t]{2}{*}{ PAHs } & \multicolumn{5}{|c|}{ Dettenhausen $(n=52):$ winter $2005 / 2006$} & \multicolumn{3}{|c|}{ Bechtoldsweiler $(n=36)$ : winter $2006 / 2007$} \\
\hline & Ring & MDL & Mean & Median & Range & Mean & Median & Range \\
\hline Naphthalene (Nap) & 2 & 0.17 & 0.08 & 0.07 & $0.02-0.4$ & 0.04 & 0.02 & $0.011-0.32$ \\
\hline Acenaphthene (Ace) & 3 & 0.08 & 0.05 & 0.03 & $0.004-0.3$ & 0.02 & 0.01 & $0.002-0.05$ \\
\hline Acenaphthylene (Acy) & 3 & 0.06 & 0.02 & 0.01 & $0.005-0.09$ & 0.03 & 0.03 & $0.029-0.03$ \\
\hline Fluorene $(\mathrm{Fl})$ & 3 & 0.12 & 0.10 & 0.08 & $0.01-0.4$ & 0.02 & 0.01 & $0.001-0.07$ \\
\hline Phenanthrene (Phe) & 3 & 0.11 & 0.95 & 0.5 & $0.13-6.7$ & 0.07 & 0.05 & $0.005-0.21$ \\
\hline Anthracene (An) & 3 & 0.06 & 0.2 & 0.07 & $0.004-1.3$ & 0.02 & 0.01 & $0.001-0.16$ \\
\hline Retene (Ret) & 3 & 0.45 & 0.7 & 0.4 & $0.02-3.4$ & 0.23 & 0.11 & $0.013-1.6$ \\
\hline Fluoranthene (Flut) & 4 & 0.41 & 2.9 & 1.4 & $0.22-19.07$ & 0.4 & 0.27 & $0.034-2.1$ \\
\hline Pyrene (Py) & 4 & 0.45 & 2.3 & 1.5 & $0.18-23.8$ & 0.5 & 0.31 & $0.033-2.3$ \\
\hline Chrysene (Chr) & 4 & 0.18 & 1.8 & 1.1 & $0.07-8.7$ & 0.5 & 0.28 & $0.014-2.1$ \\
\hline Triphenylene (Tpl) & 4 & 0.18 & 0.3 & 0.2 & $0.03-1.4$ & ND & ND & ND \\
\hline Benzo[a]anthracene $(\mathrm{BaA})$ & 4 & 0.17 & 2.3 & 1.4 & $0.19-10.5$ & 0.7 & 0.40 & $0.032-2.9$ \\
\hline Benzo[k]fluoranthene $(\mathrm{BkF})$ & 5 & 0.16 & 1.9 & 1.2 & $0.15-7.5$ & 0.8 & 0.60 & $0.046-2.6$ \\
\hline Benzo[b]fluoranthene (BbF) & 5 & 0.12 & 1.9 & 1.3 & $0.14-8.3$ & 0.7 & 0.49 & $0.051-2.4$ \\
\hline Benzo[j]fluoranthene (BjF) & 5 & 0.12 & 0.5 & 0.3 & $0.02-2.6$ & 0.2 & 0.11 & $0.012-0.8$ \\
\hline Benzo[e]pyrene (BeP) & 5 & 0.12 & 1.5 & 0.8 & $0.12-6.4$ & 0.6 & 0.45 & $0.041-1.9$ \\
\hline Benzo[a]pyrene (BaP) & 5 & 0.12 & 1.6 & 0.9 & $0.05-7.4$ & 0.8 & 0.33 & $0.021-2.5$ \\
\hline Perylene (Prl) & 5 & 0.12 & 0.3 & 0.2 & $0.01-1.4$ & 0.12 & 0.07 & $0.004-0.5$ \\
\hline Dibenzo[a,h]anthracene (DBA) & 5 & 0.11 & 0.2 & 0.2 & $0.02-0.9$ & 0.13 & 0.11 & $0.022-0.4$ \\
\hline Indeno[1,2,3-cd]pyrene (IP) & 6 & 0.28 & 1.1 & 0.7 & $0.09-4.8$ & 0.5 & 0.32 & $0.035-1.9$ \\
\hline Benzo[ghi]perylene (BghiP) & 6 & 0.37 & 1.6 & 0.9 & $0.12-7.4$ & 0.7 & 0.45 & $0.004-2.3$ \\
\hline Total PAHs & & & 23.0 & 13.3 & $1.6-121.4$ & 6.9 & 4.6 & $0.41-25.8$ \\
\hline $\mathrm{CarPAHs}^{\mathrm{a}}$ & & & 11.2 & 6.8 & $0.8-50.4$ & 4.1 & 2.8 & $0.24-15.5$ \\
\hline $\operatorname{PAH}(3,4)$ & & & 11.7 & 6.7 & $0.8-74.7$ & 2.5 & 1.5 & $0.12-10.6$ \\
\hline $\mathrm{PAH}(5,6)$ & & & 10.7 & 6.7 & $0.7-45.5$ & 4.3 & 2.9 & $0.28-15$ \\
\hline
\end{tabular}

PAHs, Polycyclic aromatic hydrocarbons; MDL, method detection limit $\left(\mathrm{ng} / \mathrm{m}^{3}\right)$; ND, not detected

${ }^{\mathrm{a}}$ Carcinogenic PAHs

Bechtoldsweiler. Because of the low concentration profiles of individual and total PAHs in Bechtoldsweiler during the winter of 2006/07, we focused subsequent analyses on the ambient concentrations of PAHs in Dettenhausen during the 2005/2006 study year.

To investigate the distribution pattern of PAHs, we classified the PAHs on the basis of the number of aromatic rings. PAH compounds with two and three rings, namely naphthalene $(\mathrm{NaP})$, acenaphthene (Ace), acenaphthylene (Acy) and fluorine (Fl) of the 16 USEPA PAH priority pollutants, have the lowest molecular mass and highest volatility, and they are present mostly in the gas phase (Bidleman et al. 1986; Sun et al. 2006; HLUG, 2006; OOE 2008). These were therefore found at relatively low concentrations in the ambient air based on the particlephase measurements. The semi-volatile PAHs are those PAHs with three and four rings [designated as $\operatorname{PAH}(3,4)$ ], such as Phe, Ant, Flut, Py, BaA and Chr. The non-volatile PAHs are those with five and six rings (designated as PAH
$(5,6)]$ and included $\mathrm{BkF}, \mathrm{BbF}, \mathrm{BjF}, \mathrm{BeP}, \mathrm{BaP}$, perylene (Prl), dibenzo[a,h]anthracene (DBA), IP and BghiP. The mean concentrations of $\operatorname{PAH}(3,4)$ and $\operatorname{PAH}(5,6)$ in the residential site Dettenhausen were 11.7 and $10.7 \mathrm{ng} / \mathrm{m}^{3}$, respectively. These values are far above the those measured in suburban residential areas in the German city of Munich, namely, $0.3-0.98 \mathrm{ng} / \mathrm{m}^{3}$ for $\mathrm{PAH}(3,4)$ and $0.5-1.9 \mathrm{ng} / \mathrm{m}^{3}$ for PAH (5,6) during 2001/2002, likely due to the dominating domestic heating fuels being gas and light oil and not wood (Schauer et al. 2003).

According to the International Agency for Research on Cancer (IARC 1987) as well as the USEPA (USEPA 1991), some PAHs have carcinogenic potential, such as $\mathrm{BaP}, \mathrm{BaA}$, $\mathrm{BkF}, \mathrm{BbF}, \mathrm{BjF}, \mathrm{DBA}$, IP, Nap and $\mathrm{Chr}$; these are designated as CarPAHs. To check the effect of carcinogenic PAHs in Dettenhausen, we measured the relative contributions of each carcinogenic PAH to the total PAHs (Fig. 5) and found that the total contribution of carcinogenic PAH compounds was $49 \%$ of the total PAHs. Most of the 


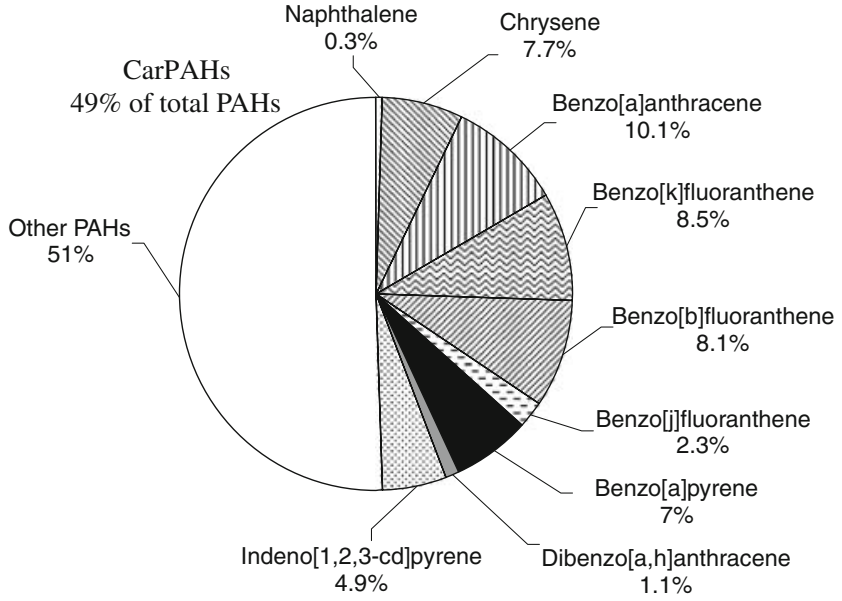

Fig. 5 Relative contribution of carcinogenic particle-phase PAHs to total PAHs at the residential site Dettenhausen

carcinogenic PAHs, especially BaA, BkF, BbF, Chr, BaP and IP, were found to be present at significant concentrations at this residential site.

During the winter of 2005/06 in Dettenhausen, the daily level of BaP, which is standardly used as a typical marker of the carcinogenicity of the PAH mixture (WHO 1987; Boström et al. 2002) ranged from 0.05 to $7.4 \mathrm{ng} / \mathrm{m}^{3}$ (median $0.9 \mathrm{ng} / \mathrm{m}^{3}$ ). In Directive 2004/107/EC (EC 2004), the European Commission (EC) set an annual target value for $\mathrm{BaP}\left(1 \mathrm{ng} / \mathrm{m}^{3}\right)$ in the ambient air based on its total content in the $\mathrm{PM}_{10}$ fraction averaged over a calendar year. The average $\mathrm{BaP}$ concentration during the measurements in the $2005 / 2006$ winter was $1.6 \mathrm{ng} / \mathrm{m}^{3}$ at the residential site. While this seems to be high, the summer concentrations are expected to be lower due to the absence of residential heating, better dispersion conditions (Baumbach 1996), better PAH degradation by photochemical and chemical oxidation (Kamens et al. 1989) and low emissions from other sources. Thus, the EU annual target value of $1 \mathrm{ng} / \mathrm{m}^{3}$ will probably not to be exceeded, but the high concentrations of $\mathrm{BaP}$ in winter time may indicate a health risk problem at the residential site. The relationship between $\mathrm{BaP}$ and total PAHs during the winter was found to be highly correlated $\left(R^{2}=0.97\right)$, suggesting that total PAHs can be used as a marker to assess $\mathrm{BaP}$ exposure. This result may indicate that the atmospheric PAHs at this residential site may be influenced by combustion-related sources, such as wood-fired domestic heating. We also found a good correlation $\left(R^{2}=0.81\right)$ between the concentrations of $\mathrm{BaP}$ and $\mathrm{PM}_{10}$, which may represent the dominant influence of wood firings on ambient $\mathrm{PM}_{10}$ concentrations. The average $\mathrm{BaP}$ concentrations obtained from the winter measurements taken at the residential site Dettenhausen are significantly higher than those found in other studies, such as in a residential site in Munich during the winter of 2002 (January-April; mean $0.20 \mathrm{ng} / \mathrm{m}^{3}$ ) (Schauer et al. 2003) and at the outskirts of Munich with a moderate traffic influence between 1996 and 1998 (range of $0.02-0.61 \mathrm{ng} / \mathrm{m}^{3}$; Schnelle-Kreis et al. 2001). In Kurkimäki, Finland, which is also influenced by residential wood combustion, the mean BaP was $1.3 \mathrm{ng} / \mathrm{m}^{3}$ (range 0.32-3.4 ng/ $\mathrm{m}^{3}$ ) during JanuaryMarch 2006 (Hellen et al. 2008), which is nearly as high as that found in this study. It should be noted that the strong barrier of surface inversions with poor vertical mixing during January and February 2006 increased the local concentrations of $\mathrm{PM}_{10}$ at our study site and, consequently, the levels of PAHs and BaP, which are caused locally from the woodfired heating (Fig. 3).
Fig. 6 Temporal profiles of carcinogenic PAHs at the residential site

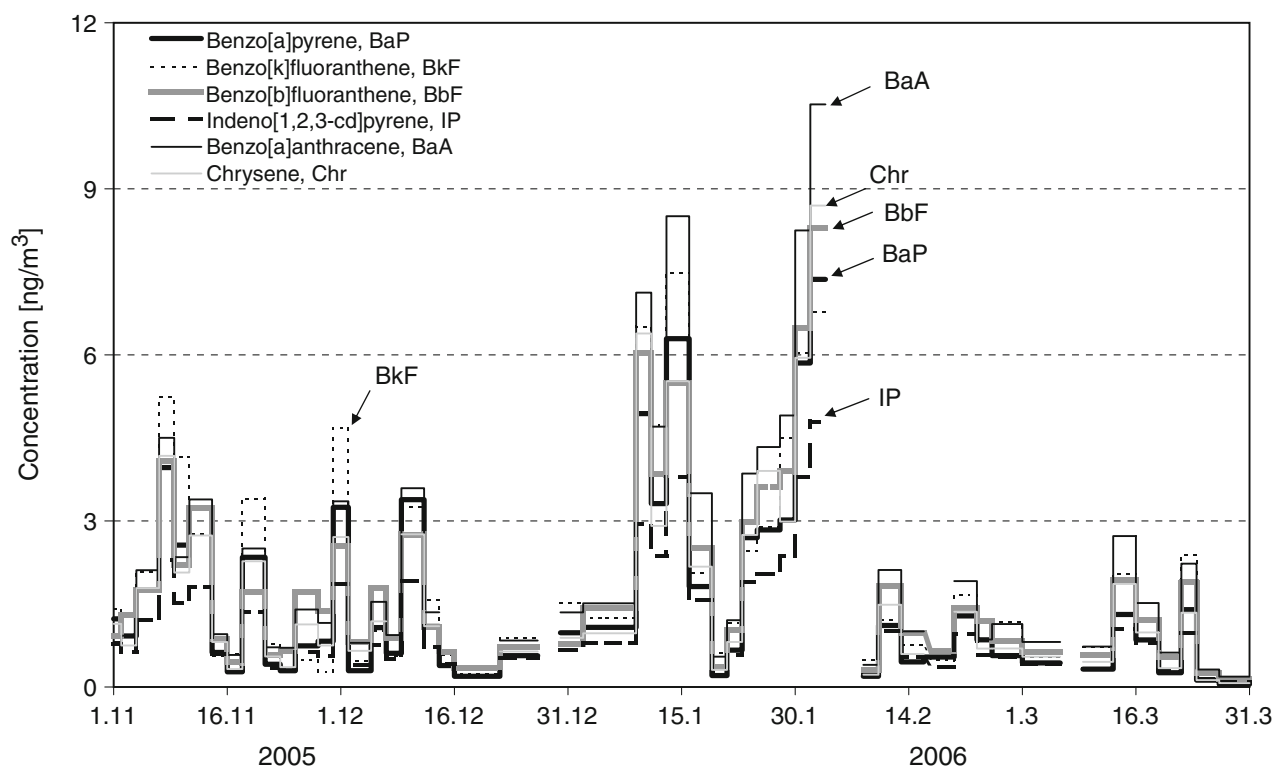


Fig. 7 Temporal profiles of other dominating PAHs at the residential site

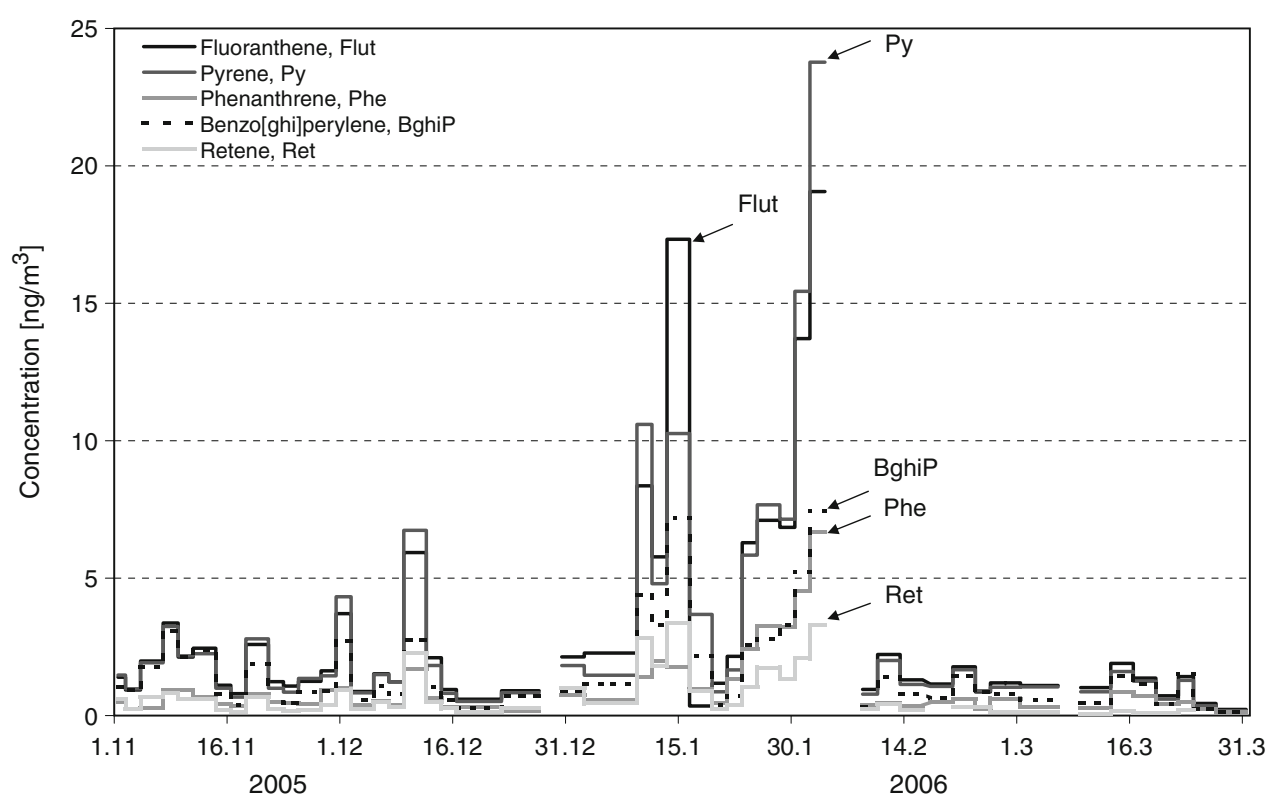

In our study, DBA concentrations ranged from 0.02 to $0.95 \mathrm{ng} / \mathrm{m}^{3}$ (median $0.20 \mathrm{ng} / \mathrm{m}^{3}$ ), which is similar to the measured values observed in 1996 in the nearest village, Waldenbuch, in earlier studies (Marbach and Baumbach 1998) and comparatively higher than the values reported for rural areas (median $0.11 \mathrm{ng} / \mathrm{m}^{3}$ ) of Germany during 19901998 (Fertmann et al. 2002). They are, however, lower than that reported for Kurkimäki, Finland (mean $0.4 \mathrm{ng} / \mathrm{m}^{3}$ ) during the winter of 2006 (Hellen et al. 2008).

The high molecular weight six-ring compounds, such as IP and BghiP, were found at significant concentrations, ranging from 0.70 to $4.8 \mathrm{ng} / \mathrm{m}^{3}$ (mean $1.1 \mathrm{ng} / \mathrm{m}^{3}$ ) and from 0.98 to $7.4 \mathrm{ng} / \mathrm{m}^{3}$ (mean $1.6 \mathrm{ng} / \mathrm{m}^{3}$ ), respectively. These concentrations are higher than the winter 2002 measurements (mean IP $0.51 \mathrm{ng} / \mathrm{m}^{3}$, mean BghiP $0.64 \mathrm{ng} / \mathrm{m}^{3}$ ) taken in suburban residential areas of Munich (Schauer 2004). These compounds were also dominant in earlier measurements taken in the nearby village Waldenbuch (Marbach and Baumbach 1998).

As people in villages use wood more intensively during the winter months, it was important to investigate a possible tracer compound for residential wood combustion. Among the PAH compounds, one typical candidate marker is retene (Ret), which results from the thermal breakdown product of resin acids present in conifer woods (Ramdahl 1983). In our study, Ret concentrations ranged from 0.02 to $3.4 \mathrm{ng} / \mathrm{m}^{3}$, with a winter average of $0.70 \mathrm{ng} / \mathrm{m}^{3}$. It should be noted that Ret can also be found in vehicular emissions (Johansson et al. 2001) and road dust (Bari et al. 2008), but these sources are not dominant at the residential site under study here.

The temporal variation in the most dominating carcinogenic PAHs, such as $\mathrm{BaP}, \mathrm{BaA}, \mathrm{BkF}, \mathrm{BbF}$, IP and $\mathrm{Chr}$, is shown in Fig. 6. Higher concentrations of $\mathrm{BaP}, \mathrm{BaA}, \mathrm{BkF}$ and $\mathrm{BbF}$ were observed in November and December, and the highest peaks were found in January and February. The two possible carcinogenic PAHs, i.e., IP and $\mathrm{Chr}$, were observed to have a pattern similar to those of the other carcinogenic compounds during the whole winter measurement period. The presence of these carcinogenic PAHs found in the winter ambient air at the residential site may indicate a potential health risk to the villagers.

The concentrations of other dominating PAHs (Flut, Py, Phe, BghiP, Ret) are depicted in Fig. 7. Flut and Py were found at comparatively higher concentrations in November and December, with the highest peaks observed during the inversion episodes in January and February. The concentrations of Phe and BghiP were comparatively lower and showed an increasing trend during the inversion episodes. Significant concentrations of Ret were observed from the beginning of the winter, with high peak concentrations during January and early February, which may clearly indicate the contribution of wood burning for domestic heating. During March 2006, when the temperature was increasing, Ret concentrations decreased, indicating less wood burning during this time.

Discussion of health risks posed by exposure to PAHs released from residential wood combustion

To assess the health risk associated with human exposure to ambient PAHs influenced by residential wood combustion, we attempted to measure exposure to individual particlephase PAHs and to carcinogenic PAHs. According to the International Agency for Research on Cancer (IARC 1987), PAH species have been classified as probable (group 2A) and possible (group 2B) human carcinogens. Due to its 
Table 2 Calculated $\mathrm{BaP}$ equivalent $\left(\mathrm{BaP}_{\text {eq }}\right)$ exposure values for the residential site

\begin{tabular}{|c|c|c|c|c|c|}
\hline PAHs & $\begin{array}{l}\text { Carcinogenic } \\
\text { group }^{\mathrm{a}}\end{array}$ & $\begin{array}{l}\text { Toxic equivalent factor } \\
(\mathrm{TEF})^{\mathrm{b}}\end{array}$ & $\begin{array}{l}\text { Ambient concentration } \\
\mathrm{ng} / \mathrm{m}^{3}\end{array}$ & $\begin{array}{l}\mathrm{BaP} \text { eq } \\
\mathrm{ng} / \mathrm{m}^{3}\end{array}$ & $\mathrm{BaP}_{\text {eq }}(\%)$ \\
\hline Naphthalene (NaP) & 3 & 0.001 & 0.08 & 0.00008 & 0.003 \\
\hline Acenaphthene (Ace) & 3 & 0.001 & 0.05 & 0.00005 & 0.002 \\
\hline Acenaphthylene (Acy) & $\mathrm{D}$ & $0.001^{\mathrm{c}}$ & 0.02 & 0.00002 & 0.001 \\
\hline Fluorene $(\mathrm{Fl})$ & 3 & 0.001 & 0.10 & 0.0001 & 0.004 \\
\hline Phenanthrene (Phe) & 3 & 0.001 & 0.95 & 0.00095 & 0.04 \\
\hline Anthracene (Ant) & 3 & 0.01 & 0.15 & 0.0015 & 0.06 \\
\hline Fluoranthene (Flut) & 3 & 0.001 & 2.92 & 0.003 & 0.11 \\
\hline Pyrene (Py) & 3 & 0.001 & 2.93 & 0.003 & 0.11 \\
\hline Chrysene (Chr) & $2 \mathrm{~B}$ & 0.01 & 1.77 & 0.018 & 0.66 \\
\hline Benzo[a]anthracene (BaA) & $2 \mathrm{~B}$ & 0.1 & 2.32 & 0.232 & 8.63 \\
\hline Benzo[k]fluoranthene $(\mathrm{BkF})$ & $2 \mathrm{~B}$ & 0.1 & 1.94 & 0.194 & 7.22 \\
\hline Benzo[b]fluoranthene $(\mathrm{BbF})$ & $2 \mathrm{~B}$ & 0.1 & 1.87 & 0.187 & 6.94 \\
\hline Benzo[j]fluoranthene (BjF) & $2 \mathrm{~B}$ & $0.1^{\mathrm{d}}$ & 0.54 & 0.054 & 2.01 \\
\hline Benzo[e]pyrene (BeP) & 3 & $0.01^{\mathrm{e}}$ & 1.48 & 0.015 & 0.55 \\
\hline Benzo[a]pyrene $(\mathrm{BaP})$ & 1 & 1 & 1.62 & 1.615 & 60.05 \\
\hline Perylene (Prl) & 3 & $0.001^{\mathrm{e}}$ & 0.27 & 0.0003 & 0.01 \\
\hline Dibenzo[a,h]anthracene (DBA) & $2 \mathrm{~A}$ & $1^{\mathrm{f}}$ & 0.24 & 0.24 & 8.99 \\
\hline Indeno[1,2,3-cd]pyrene (IP) & 2B & 0.1 & 1.11 & 0.111 & 4.14 \\
\hline Benzo[ghi]perylene (BghiP) & 3 & 0.01 & 1.61 & 0.016 & 0.60 \\
\hline Total $\mathrm{BaP}_{\mathrm{eq}}$ & & & & 2.7 & \\
\hline
\end{tabular}

${ }^{\text {a }}$ Carcinogenic to humans; $2 \mathrm{~A}$, probably carcinogenic to humans; $2 \mathrm{~B}$, possibly carcinogenic to humans; D, not classifiable as to its carcinogenicity to humans due to insufficient information to assess carcinogenic potential

${ }^{\mathrm{b}}$ TEF adopted from Nisbet and LaGoy (1992), with the exceptions of: USEPA (1991) ${ }^{\mathrm{c}}$, Collins et al. (1998) ${ }^{\mathrm{d}}$, Malcolm and Dobson (1994) ${ }^{\mathrm{e}}$, USEPA $(1993)^{\mathrm{f}}$

high carcinogenic potency and its presence in the environment, $\mathrm{BaP}$ has been defined as an indicator (group 1) of human PAH exposure. Based on the exposure or carcinogenic potency of any specific $\mathrm{PAH}$ relative to $\mathrm{BaP}$, that $\mathrm{PAH}$ may be expressed in terms of its $\mathrm{BaP}$ equivalent $\left(\mathrm{BaP}_{\mathrm{eq}}\right)$, and the carcinogenic potency of the total PAHs can be estimated from the sum of BaP equivalents (Clement Associates 1988; Krewski et al. 1989). The toxic equivalent factor (TEF) of individual PAHs relative to $\mathrm{BaP}$ carcinogenic potency has been used by several authors to calculate the $\mathrm{BaP}_{\mathrm{eq}}$ for individual PAHs (Petry et al. 1996; Collins et al. 1998; Boström et al. 2002).
Based on the lung cancer risk assessment using $\mathrm{BaP}$ as an indicator of a general PAH mixture from emissions of coke ovens and similar combustion processes in urban air, the World Health Organisation (WHO 1987) suggested a unit risk of respiratory cancer of $8.7 \times 10^{-5}(8.7$ additional cancer case per 100,000 of the population) per $\mathrm{ng} / \mathrm{m}^{3}$ for a lifetime PAH exposure of 70 years, assuming the individual was exposed to the average level of one unit $\mathrm{BaP}$ concentration of $1 \mathrm{ng} / \mathrm{m}^{3}$.

In our study, the assumptions underlying the use of the TEF approach to the estimation of exposure to PAHs have been adopted from Nisbet and LaGoy (1992), and only for DBA the TEF value was adopted from the USEPA (1993).
Table 3 Calculated BaP equivalents $\left(\mathrm{ng} / \mathrm{m}^{3}\right)$ of seven carcinogenic PAHs measured at the residential site and a comparison with other studies

\begin{tabular}{llll}
\hline Study sites & $\mathrm{BaP}_{\text {eq }} \mathrm{ng} / \mathrm{m}^{3}$ & Measurement period & Reference \\
\hline Dettenhausen & 2.6 & November 2005-March 2006 & This study \\
Nagasaki & 1.3 & $1997 / 1998$ & Wada et al. 2001 \\
Athens & 2.0 & Winter 1996 & Marino et al. 2000 \\
Bangkok & 2.1 & November 2002-April 2003 & Norramit et al. 2005 \\
Rome & 2.5 & 1996/1997 & Menichini et al. 1999 \\
Copenhagen & 6.3 & January-March 1992 & Nielsen et al. 1996 \\
\hline
\end{tabular}


As Nisbet and LaGoy (1992) did not provide TEF values for $\mathrm{BjF}, \mathrm{BeP}$ and $\mathrm{Prl}$, we used the TEF assigned by Collins et al. (1998) for BjF and the TEFs assigned by Malcolm and Dobson (1994) for BeP and Perylene. The calculated $\mathrm{BaP}$ equivalents for each individual $\mathrm{PAH}$ for ambient concentrations in the residential site are shown in Table 2. $\mathrm{BaP}_{\text {eq }}$ were derived to convert the ambient concentrations of the 19 PAHs to their BaP equivalents and finally to their total $\mathrm{BaP}_{\mathrm{eq}}$. The total personal $\mathrm{PAH}$ exposure at the residential site, i.e., total carcinogenic potency as estimated by total $\mathrm{BaP}_{\mathrm{eq}}$, was found to be $2.7 \mathrm{ng} / \mathrm{m}^{3}$. In our study, our measurements were performed on particle-phase PAHs because current discussions revolve around the health risk of PM exposure in Germany and other countries. Therefore, we referred the health risk to the particle-phase PAHs, mentioning only that there could be an additional risk via gas-phase PAHs (two- and three-ring PAHs) but this area was beyond the scope of our study. However, the additional risk presented by these PAHs would not increase very much, since the weight of these compounds in the total $\mathrm{BaP}$ equivalent is very low due to the very low toxic equivalent factors of 0.001 .

In our study, $\mathrm{BaP}$ made a $60 \%$ contribution to the exposure level of the total carcinogenic potential $\left(\mathrm{BaP}_{\mathrm{eq}}\right)$. Similar contributions of $\mathrm{BaP}(50-70 \%)$ were found in other studies in different environments (Petry et al. 1996; Papageorgopoulou et al. 1999; Boström et al. 2002), which confirms the importance of using $\mathrm{BaP}$ as an indicator of carcinogenic PAHs in ambient air. The other PAHs that contributed substantially to the total $\mathrm{BaP}_{\mathrm{eq}}$ in the ambient air were $\mathrm{BaA}$ $(8.6 \%), \mathrm{B}(\mathrm{k}+\mathrm{b}+\mathrm{j}) \mathrm{F}(16.2 \%)$, DBA $(8.9 \%)$ and IP $(4.1 \%)$, constituting an estimated $38 \%$ of total $\mathrm{BaP}$ equivalents. To compare our total $\mathrm{PAH}$ exposures (i.e., total $\mathrm{BaP}_{\mathrm{eq}}$ ) with those found in other studies, we considered the seven most carcinogenic PAHs (BaA, Chr, BbF, BkF, BaP, DBA, IP) among the 19 measured and used the same TEFs. In this case, the total $\mathrm{BaP}$ equivalent in our winter study was $2.6 \mathrm{ng} / \mathrm{m}^{3}$ (Table 3), which is higher than those reported for Nagasaki, Japan $\left(1.3 \mathrm{ng} / \mathrm{m}^{3}\right.$ for 1 year), which is characterised by high volumes of traffic, for residential areas of Athens, Greece $\left(2.0 \mathrm{ng} / \mathrm{m}^{3}\right)$ during the winter of 1996 and for traffic sites in Bangkok, Thailand $\left(2.1 \mathrm{ng} / \mathrm{m}^{3}\right)$ over a 6-month study during 2002/2003, and similar to that reported for Rome, Italy $\left(2.5 \mathrm{ng} / \mathrm{m}^{3}\right)$, which is influenced by medium traffic. It is, however, lower than that measured during short measurement periods over a 3 -month study period months in a busy street of Copenhagen $\left(6.3 \mathrm{ng} / \mathrm{m}^{3}\right)$, Denmark.

It should be noted that these comparisons of health risk of PAHs are difficult to assess because of the different time bases. The relative contribution of $\mathrm{BaP}$ and other PAHs to the total carcinogenic potential in ambient air may vary depending on the number and selection of PAH com- pounds. In our study, the $\mathrm{BaP}$ equivalent potential did not change very much when the seven carcinogenic PAHs were considered instead of the 19 total PAHs (2.6 vs. $2.7 \mathrm{ng} / \mathrm{m}^{3}$ ). Thus, from our health risk assessment, we can conclude that our results underline the importance of controlling wood smoke emissions in residential areas with the aim of maintaining a healthy air quality for the people staying there during nights with inversion situations as these limit the dispersion of the wood smoke pollutants.

\section{Summary and conclusion}

Wood is a renewable fuel and can be considered to be a sustainable energy source for domestic heating. On the other hand, if incomplete combustion takes place from manually fed wood stoves with batch combustion in residential villages, considerable amounts of PAHs can be emitted. In this study, we found that the concentrations of total PAHs at the residential site were about 3.5-fold higher during the strong winter of 2005/2006 than during the mild winter of 2006/2007. These high PAH concentrations occurred together with high $\mathrm{PM}_{10}$ concentrations during poor atmospheric exchange condition (inversions). We also found that $49 \%$ of the total particle-bound PAHs in the ambient air had a carcinogenic behaviour.

The high concentrations of wood combustion-derived PAHs found in the ambient air and the significant correlation of total PAHs with other wood smoke tracers (levoglucosan, syringaldehyde, acetosyringone) suggest that the impact of residential wood combustion (especially hardwood combustion) on ambient air quality is significant. We found that there was a good correlation $\left(R^{2}=0.81\right)$ between the most dangerous human carcinogenic PAHs, $\mathrm{BaP}$ and $\mathrm{PM}_{10}$, which may indicate that domestic wood-fired heating is a potential PAH emission source at our residential site. In our study, the total carcinogenic potency as estimated by total $\mathrm{BaP}$ equivalent was $2.7 \mathrm{ng} / \mathrm{m}^{3}$, indicating a reasonable concentration that has to be considered and avoided to prevent health risks. Thus, our findings suggest that it is very important to reduce emissions from wood-fired heating during the winter in residential areas in order to improve air quality.

The emissions of PAHs depend directly on the completeness of combustion. Thus, if the wood combustion can be improved in such a way that tends to complete combustion, the PAH emissions will be reduced drastically (Boman 2003; Johannson et al. 2004; Struschka and Brodbeck 2009). In order to use this renewable fuel more efficiently for heating purposes in residential areas, the best combustion technology should be used, such as a controlled boiler with storage tanks and, if necessary, PM filters or controlled pellet or wood chip firings. 
Acknowledgements The authors would like to thank the Institute of Combustion and Power Plant Technology and the Institute of Sanitary Engineering, Water Quality and Solid Waste Management, University of Stuttgart, for the material support for this study through a research project of the Federal Environment Agency. Aynul Bari received a doctoral grant from the Ministry of Baden-Wuerttemberg state, which is gratefully acknowledged.

Open Access This article is distributed under the terms of the Creative Commons Attribution Noncommercial License which permits any noncommercial use, distribution, and reproduction in any medium, provided the original author(s) and source are credited.

\section{References}

Bari MA (2009) Investigation of particulate matter originating from wood combustion in residential areas. $\mathrm{PhD}$ thesis. University of Stuttgart, Stuttgart

Bari MA, Baumbach G, Kuch B, Scheffknecht G (2008) Wood smoke as a source of particle-phase organic compounds in residential areas. Atmos Environ 43:4722-4732. doi:10.1016/j.atmosenv. 2008.09.006

Baumbach G (1996) Air quality control. Springer, Heidelberg, pp 83-91

Baumbach G, Struschka M (2005) Feinstäube aus BiomassefeuerungenHerausforderungen an Anlagen sowie an die Mess- und Regeltechnik. ALS (Arbeitsgruppe Luftreinhaltung der Universitaet Stuttgart) report ISBN 3-928123-37-8. University of Stuttgart, Stuttgart

Bidleman TF, Billings WN, Foreman WT (1986) Vapor particle partitioning of semi-volatile organic compounds - estimates from field collections. Environ Sci Technol 20:1038-1043. doi:10.1021/es00152a013

Boström C, Gerde P, Hanberg A, Jernström B, Johansson C, Kyrklund T, Rannug A, Törnqvist M, Victorin K, Westerholm R (2002) Cancer risk assessment, indicators, and guidelines for polycyclic aromatic hydrocarbons in the ambient air. Environ Health Perspect 110(3):451-488

Boman C (2003) Particulate matter and products of incomplete combustion from residential biomass pellet appliancesemissions and potential for future technology. Energy Technology and Thermal Process Chemistry, Umeå University, Umeå

CEN (1998) Air quality-determination of the $\mathrm{PM}_{10}$ fraction of suspended particulate matter: reference method and field test procedure to demonstrate reference equivalence of measurement methods. CEN-EN 12341 12341. CEN, Brussels

Chow JUC, Watson JG, Fujita EM, Lu ZQ, Lawson DR, Ashbaugh LL (1994) Temporal and spatial distributions of $\mathrm{PM}_{2.5}$ and $\mathrm{PM}_{10}$ aerosol in the Southern California Air Quality Study. Atmos Environ 28:2061-2080. doi:10.1016/1352-2310(94)90474-X

Clement Associates (1988) Comparative potency approach for estimating the cancer risk associated with exposure to mixtures of polycyclic aromatic hydrocarbons. ICF-Clement Associates, Fairfax

Collins JF, Brown JP, Alexeeff GV, Salmon AG (1998) Potency equivalency factors for some polycyclic aromatic hydrocarbons and polycyclic aromatic hydrocarbon derivatives. Regul Toxicol Pharmacol 28:45-54. doi:10.1006/rtph.1998.1235

Dachs J, Bayona JM, Fowler SW, Miquel JC, Albaiges J (1996) Vertical fluxes of polycyclic aromatic hydrocarbons and organochlorides in the western Alborean Sea (south-western Mediterranean). Mar Chem 52:75-86

European Commission (EC) (2001) Ambient air pollution by polycyclic aromatic hydrocarbons (PAH). Position paper. Official publications of the European Communities, Luxembourg
European Commission (EC) (2004) Directive 2004/107/EC of the European Parliament and of the Council of 15 December 2004 relating to arsenic, cadmium, mercury, nickel and polycyclic aromatic hydrocarbons in ambient air. Official Journal of the European Communities, No. L23/3, 26.1.2005, pp. 8. Brussels

Fertmann R, Tesseraux I, Schümann M, Neus H (2002) Evaluation of ambient air concentrations of polycyclic aromatic hydrocarbons in Germany from 1990 to 1998. J Expo Anal Environ Epidemiol 12:115-123. doi: $10.1038 / \mathrm{sj} / \mathrm{jea} / 7500206$

Fine PM, Cass GR, Simoneit BRT (2002) Chemical characterization of fine particle emissions from fireplace combustion of woods grown in the southern United States. Environ Sci Technol 36:1442-1451. doi:10.1021/es0108988

Fraser MP, Lakshmanan K (2000) Using levoglucosan as a molecular marker for the long-range transport of biomass combustion aerosols. Environ Sci Technol 34:4560-4564. doi:10.1021/ es9912291

Freeman DJ, Cattel CR (1990) Wood burning as a source of atmospheric polycyclic hydrocarbons. Environ Sci Technol 24:1581-1585. doi:10.1021/es00080a019

Gullett BK, Touati A, Hays MD (2003) PCDD/F, PCB, HxCBz, PAH and $\mathrm{PM}$ emission factors for fireplace and woodstove combustion in the San Francisco Bay Region. Environ Sci Technol 37:1758 1765. doi: $10.1021 / \mathrm{es} 026373 \mathrm{c}$

Hawthorne SB, Miller DJ, Lagenfeld JJ, Krieger MS (1992) $\mathrm{PM}_{10}$ high-volume collection and quantification of semi- and nonvolatile phenols, methoxylated phenols, alkanes, and polycyclic aromatic hydrocarbons from winter urban air and their relationship to wood smoke emissions. Environ Sci Technol 26:22512262. doi:10.1021/es00035a026

Harvey RG (1997) Polycyclic aromatic hydrocarbons. John Wiley \& Sons, New York

Hays MD, Smith ND, Kinsey J, Dong Y, Kariher PH (2003) Polycyclic aromatic hydrocarbon size distributions in aerosols from appliances of residential wood combustion as measured by direct thermal desorption-GC/MS. J Aerosol Sci 34:1061-1084. doi:10.1016/S0021-8502(03)00080-6

Hays MD, Beck L, Barfield P, Lavrich RJ, Dong Y, Vander Wal RL (2008) Physical and chemical characterization of residential oil boiler emissions. Environ Sci Technol 42:2496-2502. doi:10.1021/es071598e

Hays MD, Beck L, Barfield P, Willis RD, Landis MS, Stevens RK, Preston W, Dong Y (2009) Physical and chemical characterization of residual oil-fired power plant emissions. Energ Fuel 23:2544-2551. doi:10.1021/ef8011118

Hellen H, Hakola H, Haaparanta S, Pietarila H, Kauhaniemi M (2008) Influence of residential wood combustion on local air quality. Sci Total Environ 939:283-290. doi:10.1016/j.scitotenv.2008.01.019

Hessisches Landesamt für Umwelt und Geologie (HLUG) (2006) Polyzyklische aromatische Kohlenwasserstoffe. Available at: http://atlas.umwelt.hessen.de

International Agency for Research on Cancer (IARC) (1987) Monographs on the evaluation of carcinogenic risks to humans, suppl 7. IARC, Lyon, p 42

Johansson C, Wideqvist U, Hedberg E, Vesely V (2001) ITM-Institute of Applied Environmental Science ISSN 1103-341X. Stockholm University, Stockholm

Johannson LS, Leckner B, Gustavsson L, Cooper D, Tullin C, Potter A (2004) Emission characteristics of modern and old-type residential boilers fired with wood logs and wood pellets. Atmos Environ 38:4183-4195. doi:10.1016/j.atmosenv.2004.04.020

Jones PW, Leber P (1980) Polynuclear aromatic hydrocarbons: 3rd international symposium on chemistry and biology carcinogenesis and mutagenesis. Ann Arbor Science, Ann Arbor

Kamens RM, Karam H, Guo J, Perry JM, Stockburger L (1989) The behaviour of oxygenated polycyclic aromatic hydrocarbons on 
atmospheric soot particles. Environ Sci Technol 23:801-806. doi:10.1021/es00065a007

Kamm K, Röhm KH (1982) PAH und andere Schadstoffe im Abgas eines holzbefeuerten offenen Kamins. Wasser Luft Betrieb 82: $34-37$

Khalili NR, Scheff PA, Holsen TM (1995) PAH source fingerprints for coke ovens, diesel and gasoline engines, highway tunnels and wood combustion emissions. Atmos Environ 29:533-542. doi:10.1016/1352-2310(94)00275-P

Kleeman MJ, Robert MA, Riddle SG, Fine PM, Hays MD, Schauer JJ, Hannigan MP (2008) Size distribution of trace organic species emitted from biomass combustion and meat charbroiling. Atmos Environ 42:3059-3075. doi:10.1016/j.atmosenv. 2007.12.044

Krewski D, Thorslund T, Withey J (1989) Carcinogenic risk assessment of complex mixtures. Tox Ind Health 5:851-867

Lee MI, Novotny MV, Bartle KD (1981) Analytical chemistry of polycyclic aromatic compounds. Academic Press, New York

Locker HB (1988) The use of levoglucosan to assess the environmental impact of residential wood-burning on air quality. $\mathrm{PhD}$ thesis. Dartmouth College, Hanover

LUBW (2009) Federal State Baden-Wuerttemberg, Ministry of the Environment. Available at: www.lubw.baden-wuerttemberg.de

Malcolm HM, Dobson S (1994) The calculation of an environmental assessment level (EAL) for atmospheric PAHs using relative potencies. Department of the Environment, London, pp 34-46

Marbach G, Baumbach G (1998) Organische Belastung von Emissions- und Immissionsstäuben aus der Holzverbrennung. Gefahrst Reinhalt Luft 58:257-261

Marino F, Cecinato A, Siskos PA (2000) Nitro-PAH in ambient particulate matter in the atmosphere of Athens. Chemosphere 40:533-537. doi:S0045-6535(99)00308-2

Menichini E, Monfredini F, Merli F (1999) The temporal variability of the profile of carcinogenic polycyclic aromatic hydrocarbons in urban air: a study in a medium traffic area in Rome, 1993-1998. Atmos Environ 33:3739-3750. doi:S1352-2310(99)00114-4

Nielsen T, Jörgensen HE, Larsen JC, Poulsen M (1996) City air pollution of polycyclic aromatic hydrocarbons and other mutagens: occurrence, sources and health effects. Sci Total Environ 189:41-49. doi:S0048-9697(96)05189-3

Nikolaou K, Masclet R, Mouvier G (1984) Sources and chemical reactivity of polynuclear hydrocarbons in the atmosphere a critical review. Sci Total Environ 32:103-132. doi:10.1016/ 0048-9697(84)90125-6

Nisbet ICT, LaGoy PK (1992) Toxic equivalency factors (TEFs) for polycyclic aromatic hydrocarbons (PAHs). Regul Toxicol Pharmacol 16:290-300

Norramit P, Cheevaporn V, Itoh N, Tanaka K (2005) Characterization and charcinogenic risk assessment of polycyclic aromatic hydrocarbons in the respirable fraction of airborne particles in the Bangkok metropolitan area. J Health Sci 51:437-446

Oberösterreichischen Landesregierung (OOE) (2008) Polyzyklische aromatische Kohlenwasserstoffe. Available at: http://www.ooe. gv.at

Oros DR, Simoneit BRT (2001) Identification and emission factors of molecular tracers in organic aerosols from biomass burning. Part 1. Temperate climate conifers. Appl Geochem 16(13):15131544. doi:10.1016/S0883-2927(01)00021-X

Papageorgopoulou A, Manoli E, Touloumi E, Samara C (1999) Polycyclic aromatic hydrocarbons in the ambient air of Greek towns in relation to other atmospheric pollutants. Chemosphere 39:2183-2199. doi:S0045-6535(99)00143-5

Petry T, Schmid P, Schlatter C (1996) The use of toxic equivalency factors in assessing occupational and environmental healt risk association with exposure to airborne mixtures of polycyclic aromatic hydrocarbons (PAHs). Chemosphere 32:639-648. doi:10.1016/0045-6535(95)00348-7

Primbs T, Piekarz A, Wilson G, Schmedding D, Higginbotham C, Field J, Simonich SM (2008) Influence of Asian and Western United States urban areas and fires on the atmospheric transport of polycyclic aromatic hydrocarbons, polychlorinated biphenyls, and fluorotelomer alcohols in the Western United States. Environ Sci Technol 42:6385-6391. doi:10.1021/es702160d

Ramdahl T (1983) Retene - a molecular marker of wood combustion in ambient air. Nature 306:580-582

Rogge WF, Hildemann LM, Mazurek MA, Cass GR, Simoneit BRT (1998) Sources of fine organic aerosol: 9. Pine, oak, and synthetic log combustion in residential fireplaces. Environ Sci Technol 27:636-651. doi:10.1021/es960930b

Schauer C (2004) Analyse und Reaktivität von polyzyklischen aromatischen Verbindungen in Aerosolen. PhD thesis. University of Munich, Munich

Schauer JJ, Cass GR (2000) Source apportionment of wintertime gasphase and particle-phase air pollutants using organic compounds as tracers. Environ Sci Technol 35:1716-1728. doi:10.1021/ es $981312 \mathrm{t}$

Schauer JJ, Rogge WF, Hildemann LM, Mazurek MA, Cass GR (1996) Source apportionment of airborne particulate matter using organic compounds as tracers. Atmos Environ 30:3837-3855. doi:S1352-2310(96)00085-4

Schauer JJ, Kleeman MJ, Cass GR, Simoneit BRT (2001) Measurement of emissions from air pollutant sources. 3. $\mathrm{C}_{1}-\mathrm{C}_{29}$ organic compounds from fireplace combustion of wood. Environ Sci Technol 35:1716-1728. doi:10.1021/es001331e

Schauer C, Niesner R, Poschl U (2003) Polycyclic aromatic hydrocarbons in urban air particulate matter: decadal and seasonal trends, chemical degradation, and sampling artifacts. Environ Sci Technol 37:2861-2868. doi:10.1021/ es034059s

Schnelle-Kreis J, Gebefugi I, Welzl H, Jaensch T, Kettruo A (2001) Occurrence of particle-associated polycyclic aromatic compounds in ambient air of the city of Munich. Atmos Environ 35:71-81. doi:10.1016/S1352-2310(00)00557-4

Shafizadeh F (1968) Pyrolysis and combustion of cellulosic materials. Adv Carbohyd Chem 23:419-474

Simoneit BRT, Schauer JJ, Nolte CG, Oros DR, Elias VO, Fraser MP, Rogge WF, Cass GR (1999) Levoglucosan, a tracer for cellulose in biomass burning and atmospheric particles. Atmos Environ 33:173-182. doi:10.1016/S1352-2310(98)00145-9

Struschka M (1993) Holzverbrennung in Feuerungsanlagen: GrundlagenEmissionen - Entwicklung schadstoffarmer Kachelöfen. $\mathrm{PhD}$ thesis. University of Stuttgart, Stuttgart

Struschka M, Brodbeck J (2009) Toxische Wirkung von Nanopartikeln aus Biomasseverbrennung. Institute of Process Engineering and Power Plant Technology, University of Stuttgart, Stuttgart

Sun P, Blanchard P, Brice KA, Hites RA (2006) Trends in polycyclic aromatic hydrocarbon concentrations in the Great Lakes atmosphere. Environ Sci Technol 40:6221-6227. doi:10.1021/ es0607279

Tissari J, Lyyränen J, Hytönen K, Sippula O, Tapper U, Frey A, Saarnio K, Pennanen AS, Hillamo R, Salonen RO, Hirvonen MR, Jokiniemi J (2008) Fine particle and gaseous emissions from normal and smouldering wood combustion in a conventional masonry heater. Atmos Environ 42:7865-7873. doi:10.1016/j. atmosenv.2008.07.019

United States Environmental Protection Agency (USEPA) (1993) Provisional guidance for quantitative risk assessment of polycyclic aromatic hydrocarbons. U.S. Environmental Protection Agency, Research Triangle Park, NC, EPA-600/R-93/ 089 
United States Environmental Protection Agency (USEPA) (1977) Sampling and analysis procedures for screening of industrial effluents for priority pollutants. U.S. Environmental Protection Agency. Environment Monitoring and Support Laboratory, Cincinnati

United States Environmental Protection Agency (USEPA) (1991) Integrated Risk Information System. Access via USEPA: http:// cfpub.epa.gov/ncea/iris/index.cfm

Venkataraman C, Negi G, Sardar SB, Rastogi R (2002) Size distributions of polycyclic aromatic hydrocarbons in aerosol emissions from biofuel combustion. J Aerosol Sci 33:503-518
Wada M, Kido H, Kishikawa N, Tou T, Tanaka M, Tsubokura J, Shironita M, Matsui M, Kuroda N, Nakashima K (2001) Assessment of air pollution in Nagasaki city: determination of polycyclic aromatic hydrocarbons and their nitrated derivatives, and some metals. Environ Poll 115:139-147. doi:10.1016/S02697491(01)00093-8

World Health Organisation (WHO) (1987) Air quality guidelines for Europe. WHO regional publication. European Series No. 23. World Health Organisation, Copenhagen

Yu ML, Hites RA (1981) Identification of organic compounds on diesel exhaust soot. Anal Chem 53:951-954 